\title{
Inclusão escolar e autismo: uma análise da percepção docente e práticas pedagógicas
}

\author{
Carlo Schmidt \\ Universidade Federal de Santa Maria - RS - Brasil \\ Débora Regina de Paula Nunes' \\ Universidade Federal do Rio Grande do Norte, Natal - RN - Brasil \\ Débora Mara Pereira \\ Instituto Federal de Santa Catarina, Florianópolis - SC - Brasil \\ Vivian Fátima de Oliveira \\ Universidade do Planalto Catarinense, Lages - SC - Brasil \\ Adriano Henrique Nuernberg \\ Universidade Federal de Santa Catarina, Florianópolis - SC - Brasil \\ Cristiane Kubaski \\ Universidade Federal de Santa Maria - RS - Brasil
}

\begin{abstract}
Resumo: Em consonância com o Paradigma da Educação Inclusiva, a Política Nacional de Proteção dos Direitos da Pessoa com Transtorno do Espectro do Autismo (TEA) assegura que as crianças com TEA sejam matriculadas na escola regular. A presença desses educandos em classes comuns tem crescido de forma expressiva nos últimos três anos. Esse fenômeno é descrito em teses e dissertações que analisam, precisamente, as concepções e práticas de professores sobre a inclusão escolar dessa população. $\bigcirc$ objetivo deste estudo é sintetizar, por meio de uma metodologia de análise secundária de dados, estudos dessa natureza. Os participantes foram 38 professores descritos em seis pesquisas publicadas entre 2013 e 2015 . Os resultados encontrados sugerem que o autismo é uma condição pouco conhecida pelos docentes, que se sentem despreparados para educar essa população. O presente trabalho ressalta a importância da formação continuada a fim de melhor preparar os professores para atuar em classes inclusivas.
\end{abstract}

Palavras-chave: inclusão escolar; transtorno do espectro autista; percepção docente; práticas pedagógicas; revisão de literatura.

\section{SCHOOL INCLUSION AND AUTISM: A REVIEW OF TEACHER PERCEPTION AND PEDAGOGICAL PRACTICES}

\begin{abstract}
In line with the Paradigm of Inclusive Education, the National Policy on the Rights of Persons with Autism Spectrum Disorder (ASD) guarantees the enrollment of children with ASD in regular schools. As a result, the presence of these students in regular classes has grown significantly in the last three years. This phenomenon is described in theses and dissertations that precisely analyze teacher practices and conceptions concerning school inclusion of this population. The aim of this study is to synthesize, through a secondary analysis methodology, studies of this nature. Participants were 38 teachers described in six studies published between 2013 and 20I5. The results suggest that teacher knowledge of autism is limited and that these professionals feel unprepa-
\end{abstract}

${ }^{1}$ Endereço para correspondência: Débora Regina de Paula Nunes, Universidade Federal do Rio Grande do Norte (UFRN), Rua Antônio Madruga, 1982, apto. 1304, Capim Macio - Natal - RN. CEP: 59082-120. E-mail: deboranunes@ufrnet.br. 
red to educate this population. This study calls attention to the importance of continuing education in order to better prepare teachers to work in inclusive classes.

Keywords: school inclusion; autism spectrum disorder; teacher perception; pedagogical practices; literature review.

INCLUSIÓN ESCOLAR Y AUTISMO: PERCEPCIÓN DE LA ENSEÑANZA Y LAS PRÁCTICAS PEDAGÓGICAS

\begin{abstract}
Resumen: De acurdo con el paradigma de la Educación Inclusiva, la Política Nacional de Protección de los Derechos de las Personas con Trastorno del Espectro Autista (TEA) asegura que los niños con ASD estén inscritos en las escuelas regulares. La presencia de estos estudiantes en las clases regulares ha crecido en los últimos años. Este fenómeno se describe en las tesis y disertaciones sobre las concepciones y prácticas de los maestros en la inclusión escolar de esta población. El objetivo de este trabajo es sintetizar a través de una metodología de análisis de datos secundarios, los estudios de esta naturaleza. Los participantes fueron 38 profesores de seis estudios publicados entre 2013 y 2015 . Los resultados sugieren que el autismo es un trastorno poco conocido por los profesores que se sienten preparados para educar a esta población. Este estudio destaca la importancia de la formación continua para preparar mejor a los maestros para trabajar en clases inclusivas.
\end{abstract}

Palabras clave: inclusión escolar; trastorno del espectro autista; percepción de docentes; prácticas pedagógicas; revisión de literatura.

O Transtorno do Espectro do Autismo (TEA) envolve um conjunto de transtornos neurodesenvolvimentais de causas orgânicas, caracterizado por dificuldades de interação e comunicação que podem vir associadas a alterações sensoriais, comportamentos estereotipados e/ou interesses restritos. Sua manifestação é muito diversa e seus sinais, embora comumente presentes na infância, podem surgir somente quando as demandas sociais extrapolarem os limites de suas capacidades (American Psychiatric Association, 2013).

Pesquisas sobre a prevalência do autismo apontam para um crescimento significativo do número de casos diagnosticados. Estudos norte-americanos, por exemplo, sugerem que para cada 68 crianças nascidas, uma possui esse transtorno (Wingate et al., 2014). No Brasil, o estudo epidemiológico de Paula, Fombonne, Gadia, Tuckman, \& Rosanoff (2011) indica que cerca de 600 mil pessoas tenham TEA ( $0,3 \%$ da população). Alertam esses autores, contudo, cruzando com outros dados internacionais e considerando os casos ainda não diagnosticados, essa estimativa pode ser muito maior.

Esses dados se traduzem em desafios para a adequação dos diversos contextos sociais e institucionais para inclusão das pessoas com TEA. Dentre esses contextos, destaca-se a escola que, à luz das políticas inclusivas atuais, visa ampliar o acesso desses educandos às classes regulares. Em termos legais, três documentos alicerçam essa prática. Primeiramente, ressalta-se a Política Nacional de Educação Especial na Perspectiva da Educação Inclusiva, que inclui esse alunado como público-alvo da educação especial (Brasil, 2008b). Em seguida, assinala-se a Política Nacional de Proteção dos Direitos da Pessoa com Transtorno do Espectro Autista que, dentre suas diretrizes, trata do incentivo à formação e capacitação de profissionais especializados no atendimento a essa população (Brasil, 2012). Por fim, destaca-se a Nota Técnica n. 24, emitida 
pelo Ministério de Educação, que orienta os sistemas de ensino a efetivarem ações para a inclusão da pessoa com TEA (Brasil, 2012).

Apesar do direito legal de acesso à educação, a presença desse alunado na classe comum permanece um desafio aos educadores (Nunes, Azevedo, \& Schmidt, 2013). Nessa perspectiva, diversos estudos nacionais, produzidos nos últimos dez anos, têm investigado as concepções e práticas de professores sobre a escolarização de educandos com TEA em contextos regulares de ensino (Alves, 2005; Camargo \& Bosa, 2009; Fonseca, 2009; Goes, 2012; Gomes \& Mendes, 2010; Gomide, 2009; Martins, 2007; Pimentel \& Fernandes, 2014; Rodrigues, Moreira, \& Lerner, 2012; Salgado, 2012; Santos, 2009). Essas pesquisas revelam que o sentimento de despreparo tem sido prevalente entre os professores de educandos com autismo, que atuam no contexto da sala de aula regular (Pimentel \& Fernandes, 2014; Salgado, 2012). Nesse cenário, embora muitos docentes afirmem serem favoráveis à inclusão, outros alegam que a escola inclusiva seja inviável ao aluno com autismo (Salgado, 2012).

A falta de conhecimento, resultante de lacunas na formação inicial e continuada e, particularmente, percepções romantizadas do autista, como um ser preso a um mundo próprio e inacessível, parecem negativamente impactar a prática pedagógica dos docentes (Alves, 2005; Camargo \& Bosa, 2009; Martins, 2007). A baixa expectativa acadêmica associada à ideia de escola como "espaço para a socialização" do educando parecem limitar o acesso dessa população ao currículo regular (Gomes \& Mendes, 2010; Martins, 2007). Nessa perspectiva, os professores raramente fazem ajustes aos currículos ou realizam adaptações curriculares adequadas (Gomes \& Mendes, 2010; Martins, 2007). Adicionalmente, alguns estudos salientam que os docentes enfatizam a aprendizagem de habilidades funcionais, em detrimento de conteúdos formais (Gomide, 2009). Como resultado, muitos educandos encontram-se defasados academicamente (Gomes \& Mendes, 2010; Rodrigues, Moreira, \& Lerner, 2012).

Apesar da relevância desses achados, é incipiente o número de estudos que sintetizem esses resultados (Nunes, Azevedo, \& Schmidt, 2013) e que valorizem a perspectiva dos docentes como protagonistas da educação inclusiva. Assim, a presente pesquisa visa sintetizar as concepções e práticas dos professores que atuam com educandos com TEA em classes regulares. Essa síntese é fundamental para avaliar o cenário atual da inclusão escolar desses estudantes.

\section{Método}

Uma metodologia qualitativa de revisão secundária de dados (Heaton, 2004; Thorne, 2013) foi empregada. Nesta modalidade de pesquisa, dados coletados em estudos produzidos anteriormente são reanalisados com o propósito de refinar ou suplementar os achados originais, assim como responder novas questões investigativas (Heaton, 2004; Thorne, 2013). Atendendo ao primeiro propósito, o objetivo desta investigação foi depurar os achados originais de estudos que analisaram, dentre outras variáveis, as concepções e práticas de professores que atuavam com educandos com TEA em classes regula- 
res. O foco seriam as entrevistas conduzidas com os professores que, enquanto dados secundários, seriam (re)analisadas por meio da análise de conteúdo (Bardin, 2009).

Nesse modelo investigativo, depois da identificação do objetivo da pesquisa, a amostra é selecionada, considerando critérios de inclusão e exclusão previamente delineados (Heaton, 2004). Teses e dissertações nacionais publicadas em Programas de Pós-Graduação formaram a amostra, sendo incluídos apenas estudos cujos participantes fossem professores ou professores-auxiliares que atuassem em classes regulares tendo, ao menos, um aluno com TEA matriculado. Ademais, só poderiam ser considerados os trabalhos que contivessem segmentos de entrevistas com os participantes, abordando as práticas pedagógicas e percepção docente sobre o autismo.

Outro critério de inclusão foi o período de publicação das pesquisas. Os pressupostos metodológicos da análise secundária de dados orientam a selecionar um período de corte, de forma a favorecer a compreensão de um determinado fenômeno (Finfgeld-Connet, 2014). Assim, optou-se por selecionar um período em que a escolarização de educandos com TEA em classes regulares fosse garantida por Lei. Dessa forma, foram incluídos apenas estudos publicados entre 2013 e 2015, data posterior à publicação da Lei n. 12.764, vigente em dezembro de 2012, que assegura o direito da pessoa com TEA à escola regular.

Uma busca foi realizada por dois pesquisadores, de forma independente, na Biblioteca Digital Brasileira de Teses e Dissertações, utilizando como descritores os termos autismo, transtorno do espectro autista, transtorno global do desenvolvimento, inclusão, educação especial, professores, percepção e representação social. Como não foram encontrados estudos que atendessem a esse critério, procedeu-se por buscas em repositórios de programas de pós-graduação, limitando a pesquisa à área da Educação, na modalidade lato sensu. Foram localizados 126 programas na base de dados da Capes, sendo realizada uma seleção randômica de dois programas por região.

Três graduandas do curso de Pedagogia da UFRN foram instruídas a realizar a busca, considerando os respectivos descritores. A primeira analisou as produções dos 19 programas do Nordeste e 14 do Centro-Oeste. A segunda acessou os 59 do Sudeste e a terceira reviu os 9 da região Norte e 25 do Sudeste. Foi acordado que os dois primeiros trabalhos encontrados em cada região seriam incluídos na amostra, que seria composta, então, por 10 estudos.

A decisão de delimitar a amostra a esse número foi ancorada em dois argumentos pontuados por Finfgeld-Connet (2014). Primeiro, o emprego da análise de conteúdo em revisões sistemáticas deve ser criterioso, pois a análise torna-se complexa na medida em que a amostra é ampliada. Adicionalmente, a inclusão exaustiva de informações tende à redundância e à perda de dados relevantes que precisam ser destacados.

Com base nos critérios previamente salientados, foram identificados 6 estudos sendo 1 do Nordeste (Pereira, 2014), 2 do Sul (Kubaski, 2014; Oliveira, 2015), 2 do Sudeste (Gonring, 2014; Pinto, 2014) e 1 do Centro-Oeste (Silva, 2014). Não foram encontrados trabalhos publicados entre 2013 e 2015 nos nove programas analisados da região Norte. 
No modelo proposto por Heaton (2004), a análise dos dados é realizada na fase subsequente. Assim, foi elaborada uma tabela contemplando as características sociodemográficas e formativas dos participantes, assim como segmentos das entrevistas conduzidas. Em seguida, as falas dos docentes foram examinadas por meio de análise de conteúdo (Bardin, 2009).

Utilizando uma abordagem indutivo-construtiva, buscou-se extrair a significação dos conteúdos por meio de procedimentos sistemáticos, exaustivos e objetivos. Foram utilizados dois eixos de análise estabelecidos a priori: 1. Percepção sobre Características do Autismo; e 2. Práticas Pedagógicas. As respostas dos docentes foram classificadas em categorias temáticas e, posteriormente, descritas para atender o critério de exclusão mútua. Por fim, na construção de uma análise quantitativa, foram observadas as distribuições de frequência nas diferentes categorias, bem como suas respectivas porcentagens.

A classificação das respostas das professoras com as respectivas categorias foi realizada por meio de consenso entre quatro pesquisadores, sendo posteriormente avaliada por um juiz independente. Encontrou-se um índice de $87 \%$ de concordância para a Percepção sobre as Características do Autismo e 78,2\% para as Práticas Pedagógicas.

\section{Resultados}

Os seis estudos analisados contemplaram um total de 37 professores que atuavam com educandos com TEA, com idade entre 4 e 15 anos $(m=6,13 ; D P=3,11)$, distribuídos entre a Educação Infantil (26,67\%) e o Ensino Fundamental (73,33\%), em escolas públicas e privadas alocadas em seis cidades de quatro estados brasileiros, sendo 13 de Santa Catarina, dois do Rio Grande do Norte, quatro do Rio Grande do Sul, 11 do Espírito Santo e 8 do Distrito Federal. Um dos estudos (Silva, 2014) não descreveu os dados sociodemográficos e formativos dos oito participantes da amostra e seus alunos, relatando apenas que se tratava de professores de escolas regulares que lecionavam para alunos com autismo.

Os estudos analisados forneceram dados sociodemográficos e formativos de 29 participantes. Desses, 16 eram professores regentes; 8, professores auxiliares ou segundos professores; 2, professores de educação física; 1, professora de artes; 1, professor colaborador de inclusão; e 1 que atuava no Atendimento Educacional Especializado com educandos com TEA. A maior parte desses era graduada em pedagogia sem formação complementar $(51,72 \%)$, seguida por aqueles que possuíam pós-graduação lato ou stricto sensu $(37,93 \%)$ e os que estavam com a formação em curso (10,35\%). A idade deles era entre 25 e 57 anos ( $m=37,50 ; D P=9,39)$ e atuavam na docência entre 1 e 26 anos ( $m=9,98 ; D P=7,62$ ). Três não haviam lecionado para essa população, enquanto os outros tinham experiência entre um e cinco anos com esses educandos $(m=1,89 ; D P=1,58)$.

Dois grandes eixos de análise foram extraídos nessa síntese. O primeiro diz respeito às percepções dos professores sobre as características do autismo, as quais foram agrupadas em categorias pertencentes à área de sociocomunicação, comportamental e características de aprendizagem e desafios da inclusão. O segundo eixo refere-se às 
práticas pedagógicas dos professores, as quais geraram categorias sobre as adaptações e estratégias de ensino utilizadas, as dificuldades e recursos ante a inclusão, ou seja, fatores que dificultaram ou auxiliaram os professores nesse processo, e demais aspectos relatados sobre a inclusão de alunos com TEA.

As especificidades de cada Eixo de Análise serão discutidas em seguida e exemplificadas com as falas dos docentes investigados. Cada professor será identificado pela letra " $P$ " seguida de um número e o nome do autor da pesquisa.

\section{Eixo I: Percepção sobre as características do TEA}

A categoria Sociocomunicação incluiu os relatos dos professores a respeito de sua percepção sobre as características da comunicação social e comportamentos e interesses restritos de seus alunos com autismo, entre outras. Observou-se que duas características da sociocomunicação foram mais frequentemente identificadas nos estudos. A primeira revela a percepção da pessoa com autismo como um sujeito que "vive em um mundo à parte", em "uma realidade paralela" $(21,6 \%)$, e a segunda remete a comportamentos de isolamento, retração e distanciamento social $(21,6 \%)$. Embora os conteúdos apresentem-se de forma similar, é importante notar que se diferenciam porque os relatos da primeira descrevem o aluno com TEA como inacessível a intervenções externas, como as práticas pedagógicas do professor, enquanto a segunda descreve dificuldades sociais, como a retração e o distanciamento, sem a conotação de impossibilidade de acesso.

Teoricamente, tais crenças tendem a influenciar de modo diferente os comportamentos do professor ante esses alunos, percebendo-os como passíveis ou não de uma intervenção externa. Enquanto alguns professores descreveram os comportamentos de retração social do aluno, conforme evidenciado na fala, "Autismo me vem assim, uma criança mais quietinha" (P4: Oliveira, 2015); outros relataram essas características como impedindo uma intervenção pedagógica ou aproximação dos colegas, como revela o segmento, "Devido a esse isolamento total dele, é claro que as crianças também não o procuram" (P2: Pereira, 2014).

Ainda, na categoria Sociocomunicação, os relatos dos professores mostram que os alunos com TEA são percebidos a partir de seus déficits de comunicação verbal $(8,1 \%)$, não verbal $(2,7 \%)$ e comportamentos de brincar $(10,8 \%)$. Essa característica é expressa em "Ele não sabe usar o corpo para se comunicar" (P1: Pereira, 2014) e "dificuldades na fala" (P10: Oliveira, 2015), assim como vocabulário e brincadeira restritos "Brinquedo já é mais difícil dela fazer uma brincadeira mais simbólica" (P18: Kubaski, 2014).

Quanto à área comportamental, a análise gerou a categoria Comportamentos e Interesses Restritos e Repetitivos, onde os relatos destacam a percepção do aluno com TEA a partir de seus comportamentos estereotipados (13,5\%) e interesses restritos $(5,4 \%)$. Dentre os primeiros foram evidenciados os maneirismos típicos da síndrome como o flapping ou balanceios, "abana as mãos [...] fica se chacoalhando" (P2: Pereira, 2014). Os interesses restritos são ilustrados no relato, "aquele lá gosta de dinossauros, ele sabe tudo dos dinossauros, tudo, tudo, tudo" (P31: Pinto, 2013). 
Além das categorias de comunicação social e comportamentos, emergiram outros aspectos em que as falas dos professores relatavam principalmente características da aprendizagem e desafios à inclusão. A subcategoria mais frequente (24,3\%) foi a percepção desses educandos a partir de seus comportamentos agressivos, em especial as condutas de auto e heteroagressão a colegas e professores, como no exemplo: "Ela chora, ela sai batendo nos colegas, puxando cabelo, me morde ou se morde ou bate com a cabeça na porta" (P19: Kubaski, 2014).

Outras duas subcategorias que se destacaram foram a percepção do aluno com TEA como uma forma diferente de ser, a partir de suas peculiaridades na interação e aprendizagens (13,5\%), e relatos sobre comportamentos de ansiedade, impulsividade e agitação $(18,9 \%)$. Na primeira, os conteúdos sugerem concepções do TEA como uma idiossincrasia, ou seja, um modo diferente de ser, com potencial de desenvolvimento. Ratificam essa análise trechos como, "eu percebi que tinha uma interação diferente com as crianças" (P13: Oliveira, 2015) e "ela tem a capacidade de aprender mais da maneira dela!" (P15: Oliveira, 2015).

Já os comportamentos de agitação, ansiedade e impulsividade assemelharam-se aos relatos sobre agressividade em que o aluno é descrito por características que dificultam a aprendizagem e interação em sala, como ser inquieto. Dentre os segmentos que corroboram com essa perspectiva estão, "Ele não fica o tempo todo sentado ele levanta, ele caminha pela sala, ele vai na minha mesa" (P16: Kubaski, 2014), ou impulsividade "impulsividade que ele demonstra em função do seu autismo" (P24: Silva, 2014). Nesses relatos, o aluno também foi percebido como imprevisível por causa dessas características, como observado em "é uma pessoa que faz o que pensa, não mede consequência e faz o que der na telha" (P11: Oliveira, 2015).

\section{Eixo 2: Práticas Pedagógicas}

Neste eixo, dos temas que emergiram dos relatos constam as adaptações ou estratégias utilizadas pelos professores para promover a participação e o aprendizado do aluno com TEA, as quais foram categorizadas a partir de seus objetivos pedagógicos.

Dentre essas práticas, a mais frequentemente relatada $(18,9 \%)$ foi aquela em que o professor planeja a atividade de acordo com seu conhecimento prévio sobre as características, gostos ou preferências do aluno. Uma das falas que sintetizam essa perspectiva é, "ele gosta de robôs, eu separei uma série de robôs, recortei tudinho. Nossa! Ele amou aquilo tudo!" (P35: Pinto, 2013).

Também foram identificadas práticas cujo objetivo era a promoção de aprendizagens formais, como a alfabetização, presentes em 16,2\% dos relatos, e práticas para maximizar a interação e participação do aluno com TEA (10,8\%). Na primeira subcategoria foram incluídas respostas como "O maior desafio é a alfabetização [...] minha proposta é alfabetizar ele" (P17: Kubaski, 2014), enquanto a segunda pode ser ilustrada pelo segmento "A gente procura sempre que ela esteja em sala de aula, fazendo o planejamento organizado para que eles tenham essa interação" (P18: Kubaski, 2014). 
Outro tema importante refere as dificuldades encontradas na inclusão de alunos com TEA, em que os professores relataram como mais frequente o sentimento de intensa frustração e medo de lidar com determinados comportamentos do aluno $(24,3 \%)$. Segmentos que sustentam essa subcategoria são: "Deus, eu não vou conseguir trabalhar, porque ele ouve minha voz e grita, não consegue me ouvir. Me apavorei!" (P16: Kubaski, 2014); ou, ainda, "nesse momento de agressividade dele que eu pensava, meu Deus, o que eu faço agora, sabe?" (P10: Oliveira, 2015). Esses sentimentos parecem estar relacionados ao despreparo na formação, identificado em segmentos como "eu fiquei sem rumo, parece que o chão abriu. Não estou preparada pra isso" (P2: Pereira, 2014).

Esses relatos de frustração e impotência parecem estar associados, dentre outros fatores, à percepção de isolamento profissional. Nesse sentido, destacaram-se os relatos dos docentes sobre a necessidade de mais tempo para estar perto do aluno com TEA $(21,6 \%)$ e maior interação entre os professores $(16,2 \%)$, presentes em segmentos como "As dificuldades que eu achei foi de querer fazer que as coisas acontecessem e estar sozinha nesse momento [...] não ter um apoio pra você" (P12: Oliveira, 2015), ou, ainda, "o segundo professor é muito importante, só que a gente tem que ter essa troca, se não tiver essa troca pra ajudar o aluno, não vai ter progresso" (P6: Oliveira, 2015).

Ainda entre as dificuldades dos professores, os relatos sobre a pouca formação dos docentes $(16,2 \%)$ e as dificuldades em planejar, ensinar ou avaliar aprendizagens apropriadas à etapa escolar $(16,2 \%)$ se mostraram igualmente frequentes. A pouca formação se mostrou especificamente sobre conhecimentos em autismo "[...] conhecer o autismo, de uma maneira geral, saber e ver bem o que a criança tem" (P14: Oliveira, 2015), enquanto as dificuldades de ensino incluíram a falta de tempo "não se tem esse tempo hábil pra preparar atividade" (P31: Pinto, 2013), avaliar a aprendizagem "Acho difícil avaliar se ele de fato aprendeu mesmo ou se aquilo que ele demonstrou foi só naquela hora" (P1: Pereira, 2014); ou, ainda, baixas expectativas de aprendizagem, "eram atividades de pré, sabe? Ele até pega no lápis pra pintar, mas escrever ele não consegue, sabe?" (P13: Oliveira, 2015).

Quanto aos recursos na docência, 5,4\% dos professores relataram que a presença e mobilização de afeto do aluno com TEA favorecem o ensino "ela é bem carinhosa com os colegas em si" (P19: Kubaski, 2014), enquanto 2,7\% perceberam o reconhecimento de habilidades superiores na aprendizagem "Ele lê melhor do que as crianças da sala" (P20: Gonring, 2014).

Quanto aos recursos que os professores reconheceram em si, 24,3\% destacaram sua disponibilidade emocional para a docência: "Realmente você ter paciência, você ter amor" (P15: Oliveira, 2015), ou "Eu procurei sempre cativar ele, toda vez que meus alunos vão embora, todos eu beijo e me dão beijo" (P17: Kubaski, 2014). Além dessas, $8,1 \%$ das falas revelaram a persistência no ensino e a busca de alternativas pedagógico-metodológicas como um recurso importante para a docência, como mostra o relato 
"você vai ter que achar formas pra ele [...] se está com dificuldade aqui vamos frisar aqui, a prioridade é ali, é o que eu tento fazer" (P8: Oliveira, 2015).

\section{Discussão}

A percepção positiva dos professores em relação a seu aluno com autismo é um elemento fundamental para o sucesso de sua inclusão escolar (Cassady, 2011). Nesse sentido, prover suporte e orientação aos professores, fornecer uma melhor compreensão das necessidades do aluno e avaliar as estratégias eficazes para seu aprendizado são passos importantes para construção da inclusão (Cassady, 2011; Nunes, Azevedo, \& Schmidt, 2013).

Contrapondo os achados de outras pesquisas (Gomes \& Mendes, 2010; Martins, 2007) alguns professores retratados neste estudo salientaram o emprego de estratégias pedagógicas com vistas à aprendizagem de conteúdos acadêmicos. Dentre os elementos facilitadores dessa prática estão a incorporação de temáticas de interesse da criança (Pinto, 2013) e o uso de recursos visuais (Pereira, 2014). A adoção dessas estratégias é identificada em outros estudos envolvendo educandos com TEA (Banda \& Grimmett, 2008; Lanou, Hough, \& Powell, 2012, Mancil \& Pearl, 2008; Rao \& Gagie, 2006). No primeiro caso, a inclusão de objetos de interesse do aluno com autismo facilitou a aprendizagem de conteúdos acadêmicos no modelo interventivo proposto por Mancil e Pearl (2008), assim como reduziu a frequência de comportamentos disruptivos na investigação de Lanou, Hough, \& Powell (2012). No segundo, os suportes visuais suplementaram tanto a apresentação de conteúdos e seu sequenciamento quanto a transição entre uma atividade para outra no cotidiano de aprendizagem dentro e fora da sala de aula (Banda \& Grimmett, 2008).

O desafio da alfabetização do aluno com TEA foi outra temática abordada por alguns dos docentes nesta revisão (Kubaski, 2014; Oliveira, 2015; Pereira, 2014). É interessante observar que esse é um tema amplamente discorrido na literatura internacional. As pesquisas dessa natureza indicam que os programas de leitura que empregam práticas baseadas em evidência apresentam efeitos animadores em educandos com desenvolvimento típico, assim como aqueles com dificuldades leitoras. Esses mesmos programas, no entanto, não têm apresentado evidências satisfatórias em populações com autismo (Whalon, Delano, \& Hanline, 2013). Portanto, os dados sugerem que práticas alternativas de alfabetização sejam empregadas com alunos com TEA, visto que as estratégias tradicionais possam ser pouco efetivas (Whalon, Delano, \& Hanline, 2013). Tendo em vista a dificuldade docente para avaliar as aprendizagens e ensinar conteúdos acadêmicos apropriados à etapa escolar, é primordial desenvolver no Brasil uma cultura de avaliação das práticas pedagógicas empregadas para que os educandos com TEA estejam, de fato, sendo escolarizados nas escolas regulares.

Uma das questões importantes a considerar em contextos inclusivos de ensino é a interação com pares, temática pouco abordada pelos docentes neste estudo. A interação de educandos com autismo com outros colegas é limitada ou inexiste, fazendo 
que muitos manifestem comportamentos desadaptativos como uma tentativa de interação (Chamberlain, Kasari, \& Rotheram-Fuller, 2007). Conforme Camargo e Bosa (2009) revelam, a convivência da criança com autismo com pares da mesma idade constitui-se em uma oportunidade para o melhor desenvolvimento de competências e habilidades sociais, o que, por sua vez, poderá ter um impacto positivo em suas condições de aprendizagem e no desenvolvimento emocional. Por outro lado, as crianças com desenvolvimento típico também poderiam se beneficiar do contato com aquelas com autismo ao aprenderem atitudes inclusivas como a maior disposição para interagir com outras crianças com deficiência (Mavropoulou \& Sideridis, 2014). Vale ressaltar, contudo, que esse processo depende da qualidade das interações sociais desenvolvidas entre crianças com e sem autismo, mediadas por seus professores, uma vez que também há evidências da perpetuação da segregação nas salas de aula do ensino comum (Mulick \& Butter, 2002).

Com base nesses achados, um cenário preocupante é formado ao tomar como eixos de análise as concepções e práticas docentes no processo de inclusão educacional de alunos com TEA. As lacunas na formação de professores, particularmente, em relação ao conhecimento necessário para a escolarização do aluno com autismo são predominantes nas falas dos profissionais retratados nessa investigação. Em consonância com pesquisas publicadas anteriormente (Nunes, Azevedo, \& Schmidt, 2013), esse fenômeno parece contribuir para a estigmatização desses educandos, além de precarizar o emprego de práticas pedagógicas adequadas por alguns professores.

Nesse sentido, o sentimento de impotência, frustração e desamparo dos professores, associado ao medo de lidar com determinados comportamentos do aluno parece indicar um descrédito em suas próprias capacidades para adotar práticas educacionais eficazes. Infere-se, à luz da teoria social cognitiva de Bandura (1977), que existe um baixo senso de autoeficácia entre os docentes. Autoeficácia foi definida por Bandura (1977) como a crença do indivíduo sobre a sua capacidade de desempenho em atividades específicas. Essa hipótese ancora-se em quatro pilares determinantes das crenças de autoeficácia, descritas por Bandura (1977): a avaliação dos resultados da ação direta do indivíduo; as experiências vicárias; a persuasão verbal; e os estados afetivos.

Considerada a mais eficaz no desenvolvimento de forte senso de autoeficácia, a ação direta diz respeito às experiências de sucessos ou falhas vividas pelo professor, que, no cenário analisado, mostrou-se predominantemente fragilizada pelo uso de práticas pedagógicas inefetivas. As experiências vicárias, que também alicerçam as crenças, dizem respeito à aprendizagem por observação de modelos sociais. Os relatos desse estudo revelam expressivas lacunas na formação inicial dos professores, sugerindo pouco contato com o universo do autismo nos cursos de Pedagogia. Assim sendo, como seria possível aprender por observação em um cenário que não inclui esses educandos?

O terceiro pilar apontado por Bandura (1977) é a persuasão verbal, que está relacionada ao comportamento verbal de pares na avaliação das práticas docentes. O sentimento de isolamento vivenciado pelos professores analisados no presente es- 
tudo sugere haver limitada interação com outros profissionais, desde a aproximação entre regente e segundo professor até desses com equipes externas à escola. Nessa perspectiva, as possibilidades de troca e feedback positivo do trabalho pedagógico mostram-se minimizadas, impactando as crenças de autoeficácia.

Por fim, os estados afetivos, que alicerçam as crenças, também se mostram fragilizados, não só pelos sentimentos de impotência docente, mas pelas características dos educandos. Aliada à frustração e desamparo detectados nas falas dos docentes, existe a imprevisibilidade comportamental, muitas vezes, intrínseca ao educando com TEA. Esse padrão de comportamento tende a potencializar o estresse laboral sentido, o qual é interpretado como uma vulnerabilidade ao mau desempenho (Noronha \& Fernandes, 2008). Os docentes afetivamente vulneráveis tendem a não acreditar que suas práticas possam favorecer a aprendizagem dos alunos. Por outro lado, a identificação de recursos que auxiliaram os professores em sua prática docente, como a disponibilidade emocional com o aluno e crenças centradas nas potencialidades desses, por meio da persistência no ensino, pode constituir uma fonte importante de empoderamento e incremento do senso de autoeficácia.

Em face do exposto, cumpre ressaltar a necessidade de um maior suporte técnico-pedagógico aos docentes, de uma estrutura e organização escolar focada em princípios inclusivos e a consolidação da parceria entre a família e a escola. Esses são componentes recorrentemente citados na literatura e identificados nas falas analisadas como fatores de sucesso para inclusão escolar, que favorecem que as crianças com autismo tenham experiências exitosas tanto do ponto de vista da socialização quanto do aprendizado (Hansen, Blakely, Dolata, Raulston, \& Machalicek, 2014). À medida que os professores sentirem-se acolhidos em suas angústias e dúvidas e apoiados em suas decisões pedagógicas, poderão incorporar novas estratégias e (re)construir suas práticas na direção da inclusão de todos seus alunos.

\section{Referências}

Alves, M. D. (2005). As representações sociais dos professores acerca da inclusão de alunos com distúrbios globais do desenvolvimento. Dissertação de mestrado, Universidade Federal de Santa Maria, Rio Grande do Sul, RS, Brasil.

American Psychiatry Association (2013). Diagnostic and Statistical Manual of Mental Disorders. Washington: American Psychiatric Association.

Banda, D. R., \& Grimmett, E. (2008). Enhancing social and transition behaviors of persons with autism through activity schedules: A review. Education and Training in Developmental Disabilities, 43(3), 324-333.

Bandura, A. (1977). Self-efficacy: toward a unifying theory of behavioral change. Psychological Review, 84(2), 191-215. 
Bardin, L. (2009). Análise de conteúdo. Lisboa: Edições 70.

Brasil (2008b). Ministério da Educação. Secretaria de Educação Especial. Política Nacional de Educação Especial na Perspectiva da Educação Inclusiva. Brasília, 2008a. Recuperado em 13 abril, 2016, de www.mec.gov.br.

Brasil (2012). Lei n. 12.764, de 27 de dezembro de 2012. Institui a Política Nacional de Proteção dos Direitos da Pessoa com Transtorno do Espectro Autista; e altera o $\S 3^{\circ}$ do art. 88 da Lei n. 8.112, de 11 dezembro de 1990. Recuperado em 27 dezembro, 2016, de www.planalto.gov.br/ccivil_03/_ato2011-2014/2012/lei/l12764.htm.

Camargo, S. P. H., \& Bosa, C. A. (2009). Competência social, inclusão escolar e autismo: revisão crítica da literatura. Psicologia \& Sociedade, 21(1), 65-74.

Cassady, J. M. (2011). Teachers' attitudes toward the inclusion of students with autism and emotional behavioral disorder. Electronic Journal for Inclusive Education, 2(7), 1-23.

Chamberlain, B., Kasari, C., \& Rotheram-Fuller, E. (2007). Involvement or isolation? The social networks of children with autism in regular classrooms. Journal of Autism and Developmental Disorders, 37(2), 230-242.

Finfgeld-Connett, D. (2014). Use of content analysis to conduct knowledge-building and theory-generating qualitative systematic reviews. Qualitative Research, 14(3), 341-352.

Fonseca, H. V. (2009). História de vida de uma professora de alunos com autismo: constituição da identidade profissional. Dissertação de mestrado, Universidade Católica de Brasília, Brasília, DF, Brasil.

Goes, R. S. (2012). A escola de educação especial: uma escolha para crianças autistas e com deficiência intelectual associada de 0 a 5 anos. Dissertação de mestrado, Universidade de São Paulo, São Paulo, SP, Brasil.

Gomes, C. G. S., \& Mendes, E. G. (2010). Escolarização inclusiva de alunos com autismo na rede municipal de ensino de Belo Horizonte. Revista Brasileira de Educação Especial, 16(3), 375-396.

Gomide, A. B. (2009). A promoção do desenvolvimento do aluno autista nos processos educacionais. Dissertação de mestrado, Universidade Federal de Uberlândia, Uberlândia, MG, Brasil.

Gonring, V. M. (2014). A criança com síndrome de Asperger na educação infantil: um estudo de casos. Dissertação de mestrado, Universidade Federal do Espírito Santo, Vitória, ES, Brasil.

Hansen, S., Blakely, A., Dolata, J., Raulston, T., \& Machalicek, W. (2014). Children with Autism in the Inclusive Preschool Classroom: A Systematic Review of Single-Subject Design Interventions on Social Communication Skills. Review Journal of Autism and Developmental Disorders, 1(3), 192-206. 
Heaton, J. (2004). Reworking qualitative data. Sage: London.

Kubaski, C. (2014). A inclusão de alunos com Transtorno do Espectro do Autismo na Perspectiva de seus professores: estudo de caso em quatro escolas do município de Santa Maria/RS. Dissertação de mestrado, Universidade Federal de Santa Maria, Santa Maria, RS, Brasil.

Lanou, A., Hough, L., \& Powell, E. (2012). Case studies on using strengths and interests to address the needs of students with autism spectrum disorders. Intervention in School and Clinic, 47(3), 175-182.

Mancil, G. R., \& Pearl, C. E. (2008). Restricted interests as motivators: Improving academic engagement and outcomes of children on the autism spectrum. Teaching Exceptional Children Plus, 4(6), 1-15.

Martins, M. R. R. (2007). Inclusão de alunos autistas no ensino regular: concepções e práticas pedagógicas de professores regentes. Dissertação de mestrado, Universidade Católica de Brasília, Brasília, DF, Brasil.

Mavropoulou, S., \& Sideridis, G. (2014). Knowledge of Autism and Attitudes of Children Towards Their Partially Integrated Peers with Autism Spectrum Disorders. Journal of Autism and Developmental Disorders, 44(8), 1867-1885.

Mulick, J. A., \& Butter, E. M. (2002). Educational advocacy for children with autism. Behavioral Interventions, 17(2), 57-74.

Noronha, A. P. P., \& Fernandes, D. C. (2008). Estresse laboral: análise da produção científica brasileira na SciELO e BVS-Psi. Fractal: Revista de Psicologia, 20(2), 491-501.

Nunes, D. R. P., Azevedo, M. Q. O., \& Schmidt, C. (2013). Inclusão educacional de pessoas com Autismo no Brasil: uma revisão da literatura. Revista Educação Especial, 26(47), 557-572.

Oliveira, V. F. (2015). Representações Sociais de professores acerca dos seus alunos com Transtorno do Espectro do Autismo (TEA) no processo de inclusão em Escolas Municipais de Lages, SC. Dissertação de mestrado, Universidade do Planalto Catarinense, Lages, Brasil.

Paula, C. S., Fombonne, E., Gadia, C., Tuchman, R., \& Rosanoff, M. (2011). Autism in Brazil: perspectives from science and society. Revista da Associação Médica Brasileira, 57(1), 2-5.

Pereira, D. M. (2014). Análise dos efeitos de um plano educacional individualizado no desenvolvimento acadêmico e funcional de um aluno com transtorno do espectro do autismo. Dissertação de mestrado, Universidade Federal do Rio Grande do Norte, Natal, RN, Brasil.

Pimentel, A. G. L., \& Fernandes, F. D. M. (2014). A perspectiva de professores quanto ao trabalho com crianças com autismo. Audiology: Communication Research, 19(2), 171-178. 
Pinto, S. S. (2013). Práticas pedagógicas e o sujeito com autismo: um estudo de caso fenomenológico no ensino comum. Dissertação de mestrado, Universidade Federal do Espírito Santo, Vitória, ES, Brasil.

Rao, S. M., \& Gagie, B. (2006). Learning through seeing and doing: visual supports for children with autism. Teaching Exceptional Children, 38(6), 26-33.

Rodrigues, I. D. B., Moreira, L. E. D. V., \& Lerner, R. (2012). Análise institucional do discurso de professores de alunos diagnosticados como autistas em inclusão escolar. Psicologia: Teoria e Prática, 14(1), 70-83.

Salgado, A. M. (2012). Impasses e passos na inclusão escolar de crianças autistas e psicóticas: o trabalho do professor e o olhar para o sujeito. Dissertação de mestrado, Universidade Federal do Paraná, Curitiba, PR, Brasil.

Santos, M. A. (2009). Entre o familiar e o estranho: representações sociais de professores sobre o autismo infantil. Dissertação de mestrado, Universidade Federal de Pernambuco, Recife, PE, Brasil.

Silva, V. (2014). A supervalorização do diagnóstico de autismo na escola: um estudo sobre subjetividade social. Dissertação de mestrado, Universidade de Brasília, Brasília, DF, Brasil.

Thorne, S. (2013). Secondary qualitative data analysis. In C. T. Beck (Ed.). Routledge International Handbook of Qualitative Nursing Research (pp. 393-404). New York: Taylor \& Francis.

Whalon, K., Delano, M., \& Hanline, M. F. (2013). A rationale and strategy for adapting dialogic reading for children with autism spectrum disorder: RECALL. Preventing School Failure: Alternative Education for Children and Youth, 57(2), 93-101.

Wingate, M., Kirby, R. S., Pettygrove, S., Cunniff, C., Schulz, E., Ghosh, T., \& Yeargin Allsopp, M. (2014). Prevalence of autism spectrum disorder among children aged 8 years autism and developmental disabilities monitoring network, 11 sites, United States, 2010. MMWR Surveillance Summaries, 63(2), 1-21.

Submissão: 25.5.2015

Aceitação: 19.11.2015 